\title{
A Study on Challenges for Adoption of Reverse Vending Machine: A Case of North Bengaluru, India
}

\author{
Pramita S.K.*, Mamatha S.V.,Prathamesh Mhatre, Abhishek Gowda S., Deeksha R. \\ and Srikanth U. \\ Ramaiah University of Applied Sciences, India
}

\begin{abstract}
India will be producing $80-85$ MT of Solid waste by 2030. Given the alarming quantity it is imperative to bring in methods which will alleviate the problem especially the plastic waste. One of the products which helps in effective disposal of plastics is the Reverse Vending Machine (RVM). An RVM is a device which accepts bar coded plastic bottles and returns digital cash or redeemable coupons. The field study and literature show that reverse vending machine is not used extensively. This study attempts to explore the challenges for adoption of eco-friendly products like RVM. A conceptual model was built using the variables identified through literature review. The variables identified included awareness, willingness, incentives, convenience and involvement. A survey was designed and data was collected from 246 citizens to understand their views. Structural Equation Modelling was used to test conceptual model. The results emphatically show that willingness to adopt RVM was influenced by factors of involvement, convenience, awareness and incentives in that order. It is also intuitive that when involvement is high then there is an attempt to become aware and adopt eco-friendly methods which is reiterated by the results. Hence citizens have to get involved either by their own interest or by enforcing through legislation and policies to use RVM. The study concludes by recommending more policies and strategies like "bottle bill", "European Union Plastic Strategy" and Recycle Refund Systems to be mandated across the world to encourage citizens to use methods which will keep our environment plastic free.
\end{abstract}

Keywords: Reverse Vending Machine, Willingness, Plastic, Convenience, Involvement

\section{Introduction}

Waste is being generated at an increasing rate around the world, hence came the need for waste management. Waste management is the process of managing waste from the time it is produced to its final disposal. Solid waste is the largest source of waste that is generated across the world and includes paper waste, glass and ceramics, plastic waste, and tins and metals. Plastics such as PET (Poly Ethylene Terephyhalate) bottles take thousands of years to decompose. Around 5.6 million Tonnes Per Annum (TPA) of plastic waste is generated India, which is about 15,342 Tonnes Per Day (TPD). Bangalore generates $84.83 \mathrm{KG}$ of plastic per million tonnes, and is one of the top plastic producing five cities in India. The methods of recycling in India are scarce, while the foreign counterparts have brought about innovative ways to recycle materials, especially plastics. One such method of plastic waste recycling is the use of Reverse Vending Machine.

RVM is a machine that accepts used plastic bottles and in return, provides the user with money in the form of coupons/vouchers or e-wallet money. The patent for the first RVM, then known as "Bottle Return and Handling Machine", was filed in the United States of America in the year 1920. This invention came into existence due to the increase in the use of plastic bottles a form of convenience, and lack of recycling techniques for these bottles. There are more than 100,000 RVM's installed across the world and they are more common in countries with compulsory recycling laws (Sweden, Canada, Norway and others).These machines have a high popularity in the US and Canada where the law requires a refundable deposit on the containers in order to encourage recycling. The machines are commonly found around supermarkets. The 
RVM was also introduced in China, where the reward was a discount in the subway fare. Similar devices have been set up in Brazil and Japan.

In India, the concept of RVM is new, with the first one being set up only in 2016. This machine was christened as 'Swachh Bharat Recycle Machine', and was first installed in railway stations across India on World Environment day. The machine had a capacity of 500 bottles per day and only accepted bottles that had an authentic bar code. Three reward options were provided to the users - donation, mobile recharge and discounts from outlets that had a tie-up with the machine provider. The plastic was then provided to fibremanufacturing companies to be used to make grocery bags or clothes. Private companies such as Zeleno and BioCrux have set up machines in residential areas, tech parks, tourist spots and community areas. Zeleno's main objective was to show the benefits of recycling to the citizens of Delhi by attracting them with cashbacks for recycling PET bottles and aluminium cans. The company has installed around 30 machines across Delhi, Jharkhand and, Uttar Pradesh since 2016 and is in the process of installing 20 more machines. BioCrux was created with the objective of making places like residential businesses, college campuses, and commercial complexes and companies more PET-neutral. BioCrux machines have been installed in 15 locations in four cities across the country. Tomra began with a similar principal of wanting to improve the environmental situation and reduce the amount of plastic waste across the world. Terracycle with a similar principle are involved in recycling hard-to-recycle stuff. However, their rewards are not for personal benefit but for the society, through charities and donations.

The Reverse vending machines business began with the objective of reducing the amount of plastic waste across the world. Zeleno and BioCrux being solely based in India, the machines promote recycling by providing attractive incentives to users in the form of monetary benefit. Though these machines are available they are installed in limited areas and usage is minimal. This study attempts to explore the challenges which prevent the widespread usage of reverse vending machines.

\section{Literature Review}

Solid waste management is one of the primary services provided by most Governments to their citizens. Solid waste management is the most important municipal service provided to citizens. The by-products of rapid urbanization are growing faster than the rate of urbanization. It is estimated that an average urban person generates about $0.64 \mathrm{~kg}$ of municipal solid waste (MSW) per day per person (Hoornweg, Bhada-Tata \& Perinaz, 2012). Most developed countries are efficient in their ways of solid waste management, some countries also have mandatory recycling policies in place to ensure that proper waste management occurs. However, waste management is a huge problem in developing countries. The increasing amount of waste being produced in these countries is a burden to the municipal authorities due to the lack of funds that is the result of high cost management (Guerrero, Maas \& Hogland, 2013). This is a problem in India as well. The collection, transportation and disposal of waste in the country is chaotic and unscientific. Waste is transported to the outskirts of cities and towns into overflowing landfills that are impossible to reclaim. This has negative environmental implications which is the cause of groundwater pollution and global warming. In the absence of a proper system of waste segregation, recycling is a task that is done by the informal sector with their outdated technology (Gupta S, et al.,1998).

Recycling is a very important waste management process, especially for those materials that do not decompose naturally like plastic. Waste generated in developing countries composes mostly of recyclable material while the waste generated in developed countries mostly comprises of organic material (Simelane $\&$ Mohee, 2015). The rapid urbanisation has overwhelmed the municipal authorities when it comes to efficient solid waste management. Plastic waste constitutes a considerable amount of solid waste; therefore, its disposal is the most important aspect of recycling waste. Recycling is considered as one of the most environmentally sound method of waste management. (Mwanza \& Mbohwa, 2016) 
There are several techniques in place to separate Plastic Solid Waste (PSW), however these require segregation of waste with human interaction and hence is still quite inefficient. The most recent technique in recycling is mechanical recycling. This involves machines that crush plastics into different forms. The most recent type of mechanical recycling machine is the reverse vending machine, that shreds plastic bottles into flakes that can be reused in the making of fibres, clothes and ropes. In a normal mechanical recycling process, the following are the steps that occur- the machine first shreds the plastic, any contaminant is separated (paper, dust), different types of plastic are separated and then milled. The plastic is then cleaned, washed and turned into strands and single polymer plastics are formed. In the final step, the plastic is water-cooled and then sold as a final product. Therefore, recycling is the better alternative to disposing of plastics (Al-Salem,Lettieri \& Baeyens, 2009).

RVM is an innovative idea that has been introduced for collecting recycling materials, particularly plastic, aluminium and paper, and to boost recycling activities. The RVM encourages the community to dispose the waste approriately (Tomari, Kadir \& Jabbar, 2017). While the products which help recycling are available, they are not effectively utilized by the citizens. The reasons for limited utilization are varied. The comprehensive model of recycling behavior (Valle et.al. 2005) shows that the variables which influence recycling behavior include attitude towards recycling, personal norms, specific knowledge about the available recycling options, perceived convenience, governmental attitudes and personal values play an important role. The authors have mentioned that Theory of Planned Behavior (TOPB) is a good starting point to understand the factors influencing the recycling behavior. In this theory we see that the communication is not a significantly influencing behavior whereas it is intuitive that only when the different methods of recycling is communicated to the masses it creates awareness and only then it might have a higher probability of adoption. We get proof of this through the study on recycling rate (Sidique et. al., 2010). The study shows that price of waste disposal, government regulations and ordinances which make recycling mandatory, curbside recycling services and drop off centers significantly improves the rate of recycling. The author emphasizes that the educating the public to bring in awareness also influenced the rate of recycling. This study shows that convenience in terms of providing curbside services and educating to spread awareness are variables which influence the adoption of recycling methods which is also reiterated by the study conducted by Domina. \& Koch. The study by Momoh \& Oladebeye shows that awareness is an important predictor of recycling behavior. They examined the effect of convenience on recycling frequency that could be used to predict recycling behavior. The variables studied are access, shopping behaviors, income, family size and age. Irrespective of how recycling activities were defined, the study shows that the variables considered were significant predictors of recycling behavior (Domina. \& Koch, 2002). While price for waste disposal has to be affordable to improved outcomes, providing incentives will also influence the behavior of citizens towards recycling. The study related to market incentives for recycling waste packaging containers (Bor, Chien. \& Hsu, 2004) mentions that the packaging bottles have insignificant market value but with the government intervention in terms of imposing combined product charge and subsidy policies, economic incentives can be provided for processing various kinds of packaging waste. But can the economic incentives also be provided to the citizens directly and if so, intuitively they must influence the recycling behavior. When incentives are attractive enough it will create a pull in the system in terms of more citizens willing to participate in effective recycling. Literature also mentions that willingness of citizens to participate can be gauged by the extent of co-operation and commitment to a household solid waste program (Momoh \& Oladebeye, 2010). It was found that willingness to recycle is one variable that cannot always be explained by socio-demographic and socioeconomic variable. Hence for this study we feel that convenience, incentives, willingness, involvement and awareness could be studied further to understand its interrelatedness. 


\section{Literature Gaps}

The literature review focuses on solid waste management and recommends ways of disposing them through methods such as incineration and composting, however it ignores sustainable ways of disposing plastics. The papers that do address plastic and disposal through recycling discuss the parameters which may influence recycling behavior but lacks in understanding the reasons why available and sustainable recycling methods are not used. A field study was also conducted to see if the variables chosen for the study are valid.

\section{Field Study}

A field study was conducted to reconfirm the interpretations of the literature and to verify if the variables play a role in adoption of RVM. The field study was divided into two phases - to check the functionality and efficiency of RVMs and to observe the citizens' perspective towards the RVM. The existing RVMs which were installed in Cantonment Railway Station (Central Bangalore), Majestic Metro Station (Central Bangalore), Yeshwanthpur Railway Station (North Bangalore) and KSR Railway Station (East Bangalore). A sample of both citizens and retailers selling plastic bottle around the installed RVMs were interviewed to understand their knowledge about all the aspects of RVMs. The observations made were divided into three categories - Inefficiency, Dysfunctionality and Partial Dysfunctionality.

Inefficiency: The RVMs were initially difficult to locate, since the citizens were unaware of their existence. Upon locating them, it was observed that there were three screens playing videos on each side of the machine and none of them were allotted for instructions on how to redeem the cashback. The instructions, however, on how to use the RVM were written in English, making it difficult for the local citizens to understand its usage.

Dysfunctionality: Lack of maintenance of the machines was also observed in the Yeshwanthpur Railway Station, since the slot for inserting the plastic bottles was filled to the brim, blocking the entrance for more bottles. The machines were also observed to be irresponsive and showed no acknowledgement of any transaction.

Partial Dysfunctionality: In the Majestic Metro Station, a message is generated to the mobile number entered, to which the cashback was still not received.

These problems, when combined, make the process of disposing plastic waste through the RVMs extremely inconvenient and lead to the failure of the adoption. We note that field study also validates the variables selected from literature influences the usage of RVMs. Hence the following objectives were framed.

\section{Objectives}

Based on the literature review, field study and the gaps identified, our study will address the following objectives.

RO1: To study the extent of adoption of Reverse Vending Machines by citizens in North Bangalore

RO2: To analyze the factors which influence the adoption of Reverse Vending Machines

RO3: To recommend the methods and practices that improves the adoption of Reverse Vending Machines 


\section{Research Process}

The figure below (Figure 1) depicts the process which was followed to meet the objectives mentioned above.

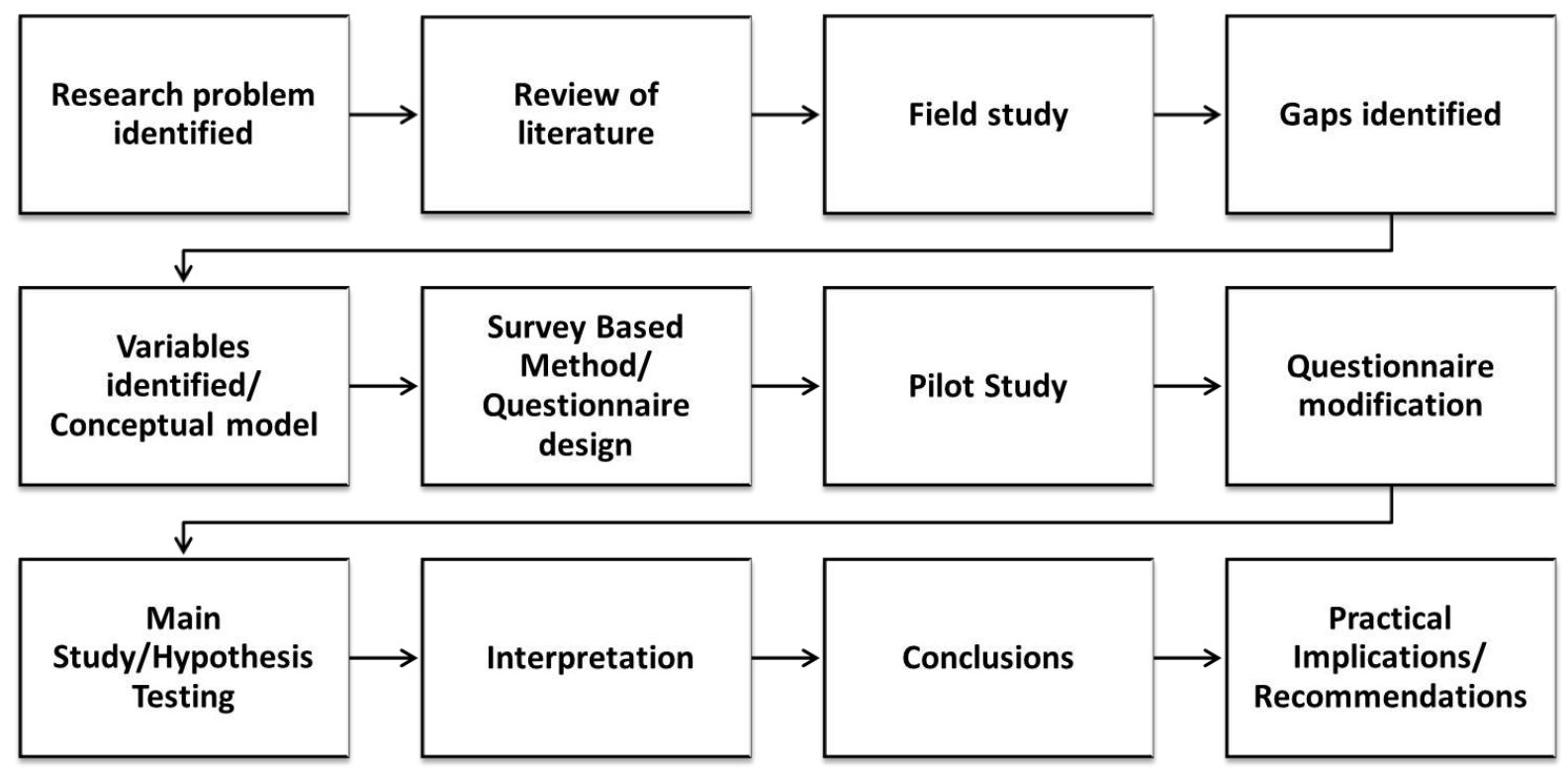

Figure 1: Research Process

The main research problem pertaining to solid waste management, mainly plastic waste management was identified. After identifying the literature gaps and performing the field study, a conceptual model was developed with five variables were identified through literature review and field study. A conceptual model was built as shown in figure 2. A cross sectional study based on survey method was seen to be appropriate for the objectives identified. A questionnaire was designed for a pilot study after receiving the feedback from 30 respondents who were part of pilot study the questionnaire was modified to improve the validity and internal consistency of the questions. Main data collection was done by uploading the questionnaire online and seeking responses from citizens. The data obtained was analyzed and results were interpreted.

\section{Research Design}

The research design explains the sampling design and questionnaire design in detail. The questionnaire consisted of two parts. Part A consisted of Demographics about the respondents' which are name, age, occupation, gender and marital status. Part B consisted of questions categorized based on the variables identified. A five-point Likert Scale was chosen. Convenience sampling was used for both pilot and main study since the citizens must be willing to participate in the study. The target audience was the citizens of North Bengaluru for the pilot and main study since two RVMs were located nearby.

\section{Conceptual Model}

The conceptual model is based on the second objective, which is to analyze the factors that influence he adoption of RVM. Figure 2 below shows a conceptual model with willingness being the dependent variable and Awareness, convenience, incentives and involvement being independent variables. The following model is derived from review of literature and field study. According to literature, Willingness is the main attribute which will influence the recycling behavior and it may be influenced by the independent variables. 


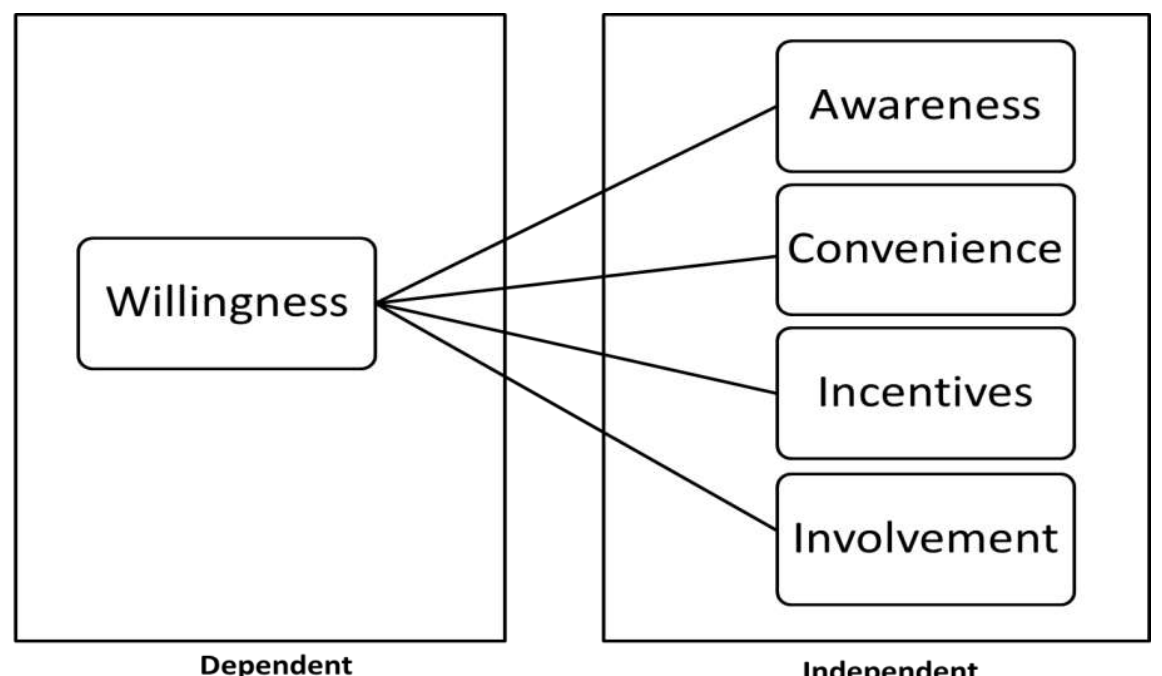

Dependent

Independent

Figure 2: The Conceptual Model

Based on the Conceptual Model (Figure 2), the following hypotheses has been developed, which is further going to be tested using the Structural Equation Modelling.

\section{Hypotheses}

$\mathrm{H} 0=$ Willingness to adopt RVM is not affected by Awareness

$\mathrm{H} 1=$ Willingness to adopt RVM is affected by Awareness

H0= Willingness to use RVM is not influenced by convenience

$\mathrm{H} 1=$ Willingness to use RVM is influenced by convenience

$\mathrm{H} 0=$ Willingness to use RVM is not affected by the incentives received

$\mathrm{H} 1=$ Willingness to use RVM is affected by the incentives received

$\mathrm{H} 0=$ Willingness to adopt RVM is not influenced by the user's level of involvement

H1 = Willingness to adopt RVM is influenced by the user's level of involvement

\section{Data Collection and Data Cleaning}

Data collection was done for both pilot and main study by uploading the questionnaire online. The target audience had to answer all the questions as it was made mandatory. The initial questionnaire consisted of 31 questions. Face validity and content validity was done by reviewing the questions with citizens and retailers. The most common feedback received from the respondents was that the questions were repetitive and were difficult to comprehend for the citizens. The questions were hence modified accordingly and used for pilot study. Construct validation was done using Cronbach alpha with the data collected for pilot study. The questions related to variables which showed Cronbach alpha less than 0.6 were modified. The modified questionnaire was 
used for main study which consisted of 26 questions. There were 247 respondents for main study. The responses were analyzed to identify cases of central tendency and they were eliminated from the data set. The sample description and the construct validation results are shown in Table 1 and Table 2.

\section{Sample Description}

Table 1: Descriptive Statistics

\begin{tabular}{|c|c|c|}
\hline Items & Pilot Study & Main Study \\
\hline Age & $\begin{array}{l}83.3 \% \text { respondents between } \\
\text { the age group of } 19-28 \text { years. }\end{array}$ & $\begin{array}{l}46 \% \text { of respondents between } \\
\text { the age group of } 19-28 .\end{array}$ \\
\hline Marital Status & $83 \%$ unmarried & $60 \%$ of them were unmarried \\
\hline Gender & $\begin{array}{l}66.7 \% \text { of the respondents were } \\
\text { male }\end{array}$ & $\begin{array}{l}\text { Almost equal number of male } \\
\text { and female respondents }\end{array}$ \\
\hline Occupation & $\begin{array}{l}73.3 \% \text { of the respondents were } \\
\text { students. }\end{array}$ & $\begin{array}{l}77 \% \text { of the respondents } \\
\text { consisted of Students and } \\
\text { Employed }\end{array}$ \\
\hline
\end{tabular}

\section{Structural Equation Modelling (SEM)}

The SEM model was used as it is commonly justified in social sciences because of its ability to analyse the relation between latent variables from the observable variables (questions from the survey). This helps to establish multiple relationships (direct and indirect) between a set of variables and can be applied to demonstrate whether the causal hypotheses embedded in a model are consistent with the data (Breckler, 1990). This model is lenient towards the assumptions of regression. We use Smart PLS 3.0 software which predominantly is a variance-based SEM also called partial least square (PLS) SEM. The software uses correlational matrix to arrive at results. The analysis is done in two steps which is first the Measurement model is generated and then the Structural model.

\section{Measurement Model}

Measurement model is generated to check for construct validity. The constructs (Latent variables) identified are shown in Table 2. The validity and reliability of the constructs are done in the first step. Cronbach alpha shows that the constructs are reliable if the values are greater than 0.6 (Nunnally \& Bernstein, 1994). Validity is defined as "the extent to which data collection methods accurately measure what they were intended to measure" (Saunders \& Thornhill, 2003) Validation is done using convergent and discriminant validations. For the constructs which are mentioned in Table 2 the convergent and discriminant validity tests have shown values above the threshold levels. Convergent validity (Average variance extracted (AVE) is greater than 0.5) for discriminant validity we use the Fornell-Larcker criterion (Fornell \& Larcker, 1981) where the shared variance of any two variables is less than the AVE.

\section{Table 2: Construct Validation}

\begin{tabular}{lll}
\hline Latent variables & $\begin{array}{l}\text { Cronbach's Alpha } \\
\text { (Pilot Data N=30) }\end{array}$ & $\begin{array}{l}\text { Cronbach's Alpha } \\
\text { (Main Data N=247) }\end{array}$ \\
\hline Awareness & 0.589 & 0.754 \\
\hline Willingness & 0.552 & 0.876 \\
\hline Incentives & 0.217 & 0.575 \\
\hline Convenience & 0.329 & 0.742 \\
\hline Involvement & 0.826 & 0.731 \\
\hline
\end{tabular}


The Pilot Data shows that the Cronbach's Alpha for all constructs except Involvement is less than 0.6. This implies that the data is not reliable. In case of the Main Study, all constructs are reliable after modification of the questionnaire, signifying that the internal consistency of these items is high. A confirmatory factor analysis was conducted to ensure that the items measured the latent variables accurately. The factor loadings are shown in Table 3. The questions related to Items shown in column 'Items' of table 3 are mentioned in Appendix (Table $6)$.

Table 3: Factor Loadings ( $\lambda$ )

\begin{tabular}{|c|c|c|c|c|c|}
\hline Items & Awareness & Convenience & Incentives & Involvement & Willingness \\
\hline AW02 & $0.810^{* *}$ & & & & \\
\hline AW03 & $0.917 * *$ & & & & \\
\hline CN01 & & $0.794 * * *$ & & & \\
\hline $\mathrm{CN} 02$ & & $0.622 * * *$ & & & \\
\hline CNO3 & & $0.775^{* * *}$ & & & \\
\hline $\mathrm{CN} 04$ & & $0.602 * * *$ & & & \\
\hline $\mathrm{CN} 05$ & & $0.733 * * *$ & & & \\
\hline IN01 & & & $0.732 * * *$ & & \\
\hline IN04 & & & $0.642 * * *$ & & \\
\hline IN05 & & & $0.729 * * *$ & & \\
\hline IV01 & & & & $0.738 * * *$ & \\
\hline IV02 & & & & $0.581 * * *$ & \\
\hline IV04 & & & & $0.829 * * *$ & \\
\hline IV05 & & & & $0.738 * * *$ & \\
\hline IV06 & & & & $0.702 * * *$ & \\
\hline WI01 & & & & & $0.858 * * *$ \\
\hline WI02 & & & & & $0.807 * * *$ \\
\hline WI03 & & & & & $0.828 * * *$ \\
\hline WI04 & & & & & $0.901 * * *$ \\
\hline WI05 & & & & & $0.684 * * *$ \\
\hline
\end{tabular}

Note: ${ }^{* * *}$ Significance at $\mathrm{p}<0.001,{ }^{* *}$ Significance at $\mathrm{p}<0.01,{ }^{*}$ Significance at $\mathrm{p}<0.05$.

Most of the loadings are above a value of 0.6. The loadings that are below 0.6 can be accepted because this study is relatively new to research. The loading "IV02" is the only loading with a value below 0.6 , but we accept it since the item is important to the study. Hence the measurement model has validated the latent variables and the instrument used to measure the latent variables. The next step is to find the relationships between these variables which is done by generating the structural model of inner model.

\section{Structural Model}

The constructs validated in the measurement model are given as inputs to the structural model. In the structural model regression lines are drawn between the independent and dependent variables as shown in the conceptual model (figure 2). The method of estimation used is maximum Likelihood Estimation (MLE). The model fit parameters, $\beta$ co-efficient, $R$ square values which is the variance explained by the model and $p$-Value or significance are collected from the structural model which is interpreted and conclusions are drawn. The results of hypothesis testing are given in Table 4. 
Table 4: Research Hypothesis Result

\begin{tabular}{|c|c|c|}
\hline Hypothesis & $\begin{array}{l}\text { Values } \\
\text { ( } \beta \text { and } p-\text { Value) }\end{array}$ & Inference \\
\hline $\begin{array}{l}\mathrm{H}_{0}=\text { Willingness to adopt RVM } \\
\text { is not affected by awareness } \\
\mathrm{H}_{1}=\text { Willingness to adopt RVM is affected } \\
\text { by Awareness }\end{array}$ & $\begin{array}{l}\beta=0.185 \\
\mathrm{p} \text {-value }=0.231 \\
\mathrm{R}^{2}=0.034\end{array}$ & $\begin{array}{l}\mathrm{H}_{0} \text { is accepted, hence } \\
\text { Awareness has no } \\
\text { effect on Willingness }\end{array}$ \\
\hline $\begin{array}{l}\mathrm{H}_{0}=\text { Willingness to use RVM is not } \\
\text { influenced by convenience } \\
\mathrm{H}_{1}=\text { Willingness to use } \mathrm{RVM} \text { is influenced } \\
\text { by convenience }\end{array}$ & $\begin{array}{l}\beta=0.452 \\
\mathrm{p} \text {-value }=0.000 \\
\mathrm{R}^{2}=0.204\end{array}$ & $\begin{array}{l}\mathrm{H}_{0} \text { is rejected, hence } \\
\text { Convenience } \\
\text { influences Willingness }\end{array}$ \\
\hline $\begin{array}{l}\mathrm{H}_{0}=\text { Willingness to use RVM is not affected } \\
\text { by the incentives received } \\
\mathrm{H}_{1}=\text { Willingness to use RVM is affected by } \\
\text { the incentives received }\end{array}$ & $\begin{array}{l}\beta=0.309 \\
\mathrm{p} \text {-value }=0.000 \\
\mathrm{R}^{2}=0.095\end{array}$ & $\begin{array}{l}\mathrm{H}_{0} \text { is rejected, hence } \\
\text { incentives influence } \\
\text { Willingness }\end{array}$ \\
\hline $\begin{array}{l}\mathrm{H}_{0}=\text { Willingness to adopt RVM is not } \\
\text { influenced by the user's level of } \\
\text { involvement } \\
\mathrm{H}_{1}=\text { Willingness to adopt RVM is } \\
\text { influenced by the user's level of } \\
\text { involvement }\end{array}$ & $\begin{array}{l}\beta=0.606 \\
\mathrm{p} \text {-value }=0.000 \\
\mathrm{R}^{2}=0.367\end{array}$ & $\begin{array}{l}\mathrm{H}_{0} \text { is rejected, hence } \\
\text { Involvement influences } \\
\text { Willingness }\end{array}$ \\
\hline
\end{tabular}

The Table above shows that involvement, convenience and awareness are the main parameters which influence willingness of people to adopt RVM. Involvement is the main variable which influences willingness. Convenience is the second most important variable which means to say that if the RVMs are convenient to use and are accessible citizens will be more willing to use. Incentives, have an impact on willingness which is significant but the variance explained is low. So, citizens are willing to use an RVM with or without incentives. Lastly, awareness does not have an impact on the willingness to use an RVM.

\section{Final Model}

The final model based on the hypothesis testing done using PLS SEM is shown in figure 3 below. We conclude that citizens are more than likely to use an RVM when they are more involved in activities that actively promote a cleaner and safer environment as well as make them convenient to use. We infer from the R2 values that Involvement and convenience are the major factors which impact Willingness. 


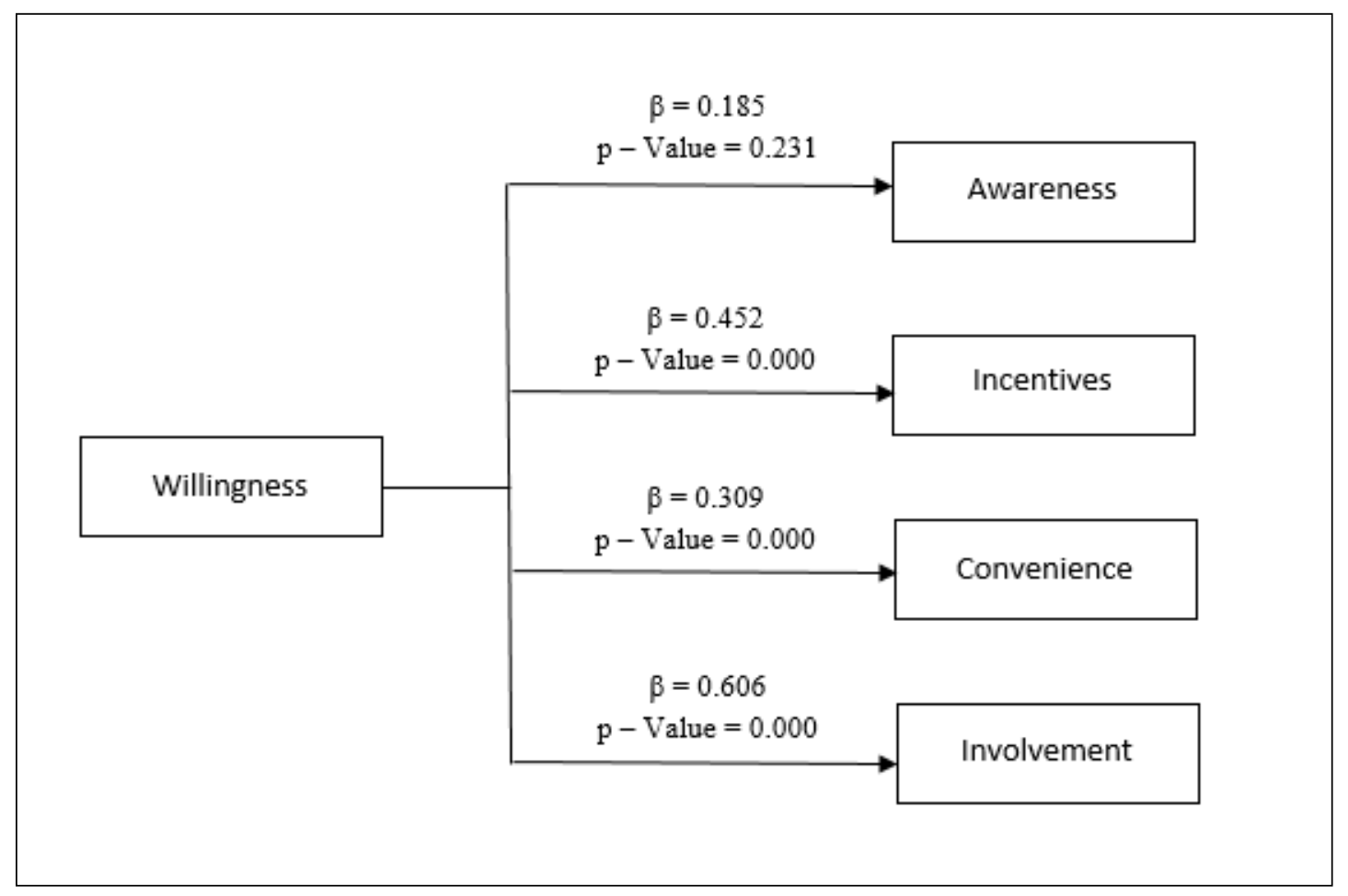

Figure 3: Final Empirical Model

\section{Multi Group Analysis}

Multi-Group Analysis (MGA) gives us insights into how relationship between variables (independent and dependent) vary based on demographic parameters captured for this study which are age, gender, marital status and occupation. MGA is done using bootstrapping. Table 5 below shows variation in the significance for different relationships.

Table 5: Multi Group Analysis

\begin{tabular}{|c|c|c|}
\hline Age & $\begin{array}{l}\text { p-Values (less than } \\
\text { 28yrs) }\end{array}$ & $\begin{array}{l}\text { p-Values (greater } \\
\text { than } 29 \text { yrs) }\end{array}$ \\
\hline Willingness -> Awareness & 0.000 & 0.324 \\
\hline Willingness -> Convenience & 0.000 & 0.000 \\
\hline Willingness -> Incentives & 0.190 & 0.209 \\
\hline Willingness -> Involvement & 0.000 & 0.000 \\
\hline Gender & p-Values (Male) & p-Values (Female) \\
\hline Willingness -> Awareness & 0.003 & 0.073 \\
\hline Willingness -> Convenience & 0.000 & 0.000 \\
\hline Willingness -> Incentives & 0.000 & 0.087 \\
\hline Willingness -> Involvement & 0.000 & 0.000 \\
\hline Marital Status & p-Values (Married) & $\begin{array}{l}\text { p-Values } \\
\text { (Unmarried) }\end{array}$ \\
\hline Willingness -> Awareness & 0.282 & 0.000 \\
\hline Willingness -> Convenience & 0.000 & 0.000 \\
\hline Willingness -> Incentives & 0.299 & 0.000 \\
\hline Willingness -> Involvement & 0.025 & 0.000 \\
\hline Occupation & p-Values (Student) & $\begin{array}{l}\text { p-Values } \\
\text { (Employed) }\end{array}$ \\
\hline Willingness -> Awareness & 0.000 & 0.200 \\
\hline Willingness -> Convenience & 0.000 & 0.000 \\
\hline Willingness -> Incentives & 0.000 & 0.049 \\
\hline Willingness -> Involvement & 0.000 & 0.000 \\
\hline
\end{tabular}


The interpretations are as follows:

Age: For citizens with age less than 28 years awareness, convenience and involvement are significant which positively influences willingness but incentives has no significant relationship. This means that even if there are no incentives this group would change the behavior towards recycling. For citizens with age greater than 28 years convenience and involvement have a significant effect on willingness. We can infer that this group would adopt recycling methods even if there are no incentives and might create awareness if something is convenient to use.

Gender: For men all variables are significantly influence willingness but for women only convenience and involvement are the significant variables which influence their willingness.

Marital Status: Citizens who are married will adopt RVM if it is convenient and if they are involved in recycling methods and green campaigns while for unmarried citizens all the variables have a significant influence on willingness.

Occupation - For students and employed there is no significant difference in the relationships.

MGA shows that age, gender and marital status act as moderators to the model while occupation does not moderate the relationships between variables.

\section{Conclusion}

The study concludes about the first objective (RO1) through literature review and field study, that RVMs are not used effectively though government and private institutions are installing them through the Corporate Social Responsibility (CSR) initiatives. The adoption of RVMs lacks awareness and involvement. The factors analyzed (RO2) are Convenience, Incentives, involvement, willingness and Awareness. The results show that involvement in recycling methods and environmental concerns is the biggest driver of willingness of citizens to adopt new methods of recycling. This concurs with the study related to Theory of Planned Behavior (Valle et.al. 2005) where recycling involvement drives the planned behavior. Convenience is the next significant contributor to improving willingness of citizens. It concurs with the study on improved recycling rate (Sidique et. al., 2010) where convenience in terms of increased drop-off points or accessible installations can drive willingness positively. It also concurs with study on improving recycling frequency (Domina, \& Koch, 2002) where ease of access influence the citizens' willingness towards recycling initiatives. Incentives also influences willingness though not to a large extent but to make it accessible to all classes of society considering this factor become important. According to Bor, Chien \& Hsu, E. (2004), in Taiwan, the government incentivizes recycling of packaging material by combined packaging charges and subsidy policy. It is important to generate economic value at all levels of society to ensure adoption of recycling methods. The study shows that there has been a marked improvement by providing market incentives. While Awareness does not show a significant influence on willingness which does not concur with the study of recycling rates (Sidique et. al., 2010), we see that this parameter is important to improve involvement.

The methods and practices that might improve adoption of RVM related to objective 3 (RO3) are as follows:

Social marketing programs that aims to improve consumer recycling involvement with a thorough model that describes how consumers adopt that behavior (Andreasen, 1995; Geller, 1989) can be designed to improve the involvement levels of citizens. For example, green campaigns and workshops can be set up for promoting awareness and educating people about the RVMs. 
Government should enforce laws that make the adoption of RVMs a mandate. RVMs can hence be installed in educational institutes, offices or places that people visit on a daily basis. The awareness and involvement would make the difference when it is placed where the citizens are educated.

India is a country where only $24 \%$ of the population owns smartphones (that can accommodate PayTM). In order to cater to the needs of common citizens who do not own smartphones alternative approaches can be used. For example, Brooke Bond sponsored the installation of a Beverage based RVM where the machines accept waste plastic bottles in exchange for a cup of tea. It is a very innovative and useful way of reaching out to the masses and provide innovative incentives which will attract all classes of society to use the machine.

The adoption of RVMs could be part of the policies of the country, where the consumer pays a deposit while purchasing commodities. If they recycle the plastic containers after consumption, they can claim refunds of the deposits from retailers. It generates strong incentives for the consumers to recycle. Policies and strategies like "bottle bill”, "European Union Plastic Strategy" and Recycle Refund Systems can be mandated across the world to encourage citizens to use methods which will keep our environment plastic free

\section{Limitations}

The limitations we found was that the study was conducted in the Bangalore North region only. Hence the findings cannot be generalized. A similar study can be conducted using a different sampling design to cover larger population and results can be generalized to larger geographical area. This study has geographic barriers. Studies based in countries like Germany, Norway and United States where the government has rules for plastic disposal are more efficient. Hence, the applicability of the model to different geographies needs to be explored. We notice that Awareness as a construct did not have a significant relation with Willingness which is counter intuitive to what the literature says. Hence this parameter needs a sharper focus to see how it helps to improve recycling behavior.

\section{Future Study}

The current study involves research upon the adoption of the RVM's in North Bengaluru. However, with further research on the government policies of other states, the adoption of RVMs for the whole country can be studied. This can also be used as a basis for significant changes in the government policies for waste management. Incentive model can be used as a reference for further implementation in various other niche products that contribute towards a social cause. The same study can be integrated with modified variables to study the willingness of the organizations to make the adoption of the RVM's part of their Corporate Social Responsibility. Instead of using willingness of the users as the dependent variable, convenience or involvement can be used for different projections or even more suitable solutions for the society. The model can be integrated with the Theory or Planned Behavior model (Valle et.al. 2005) and it can also be explored with consumer behavior models on how to engineer a recycling behavior in citizens (Andreasen, 1995; Geller, 1989).

\section{References}

Al-Salem, S., Lettieri, P. and Baeyens, J. (2009). Recycling and recovery routes of plastic solid waste (PSW): A review. Waste Management, 29(10), pp.2625-2643.

Andreasen, A.R., 1995. Marketing social change: Changing behavior to promote health, social development, and the environment (p. 101). San Francisco: Jossey-Bass.

Breckler, S. J. (1990). Applications of covariance structure modeling in psychology: Cause of concern? Psychological Bulletin, 107, 260-273.

Bor, Y.J., Chien, Y.L. and Hsu, E., 2004. The market-incentive recycling system for waste packaging containers in Taiwan. Environmental Science \& Policy, 7(6), pp.509-523. 
Domina, T. and Koch, K., 2002. Convenience and frequency of recycling: implications for including textiles in curbside recycling programs. Environment and behavior, 34(2), pp.216-238.

Fornell, C. and Larcker, D.F., 1981. Structural equation models with unobservable variables and measurement error: Algebra and statistics.

Geller, E.S., 1989. Applied behavior analysis and social marketing: An integration for environmental preservation. Journal of social issues, 45(1), pp.17-36.

Ghosh, S. (2018). India to galvanise greater action against plastic waste on World Environment Day. [online] Mongabay-India. Available From: https://india.mongabay.com/2018/04/india-to-galvanise-greater-actionagainst-plastic-waste-on-world-environment-day [Accessed 28th November 2018]

Guerrero, L., Maas, G. and Hogland, W. (2013). Solid waste management challenges for cities in developing countries. Waste Management, 33(1), pp.220-232.

Gupta, S., Mohan, K., Prasad, R., Gupta, S. and Kansal, A. (1998). Solid waste management in India: options and opportunities. Resources, Conservation and Recycling, 24(2), pp.137-154.

Hoornweg, D. and Bhada-Tata, P., 2012. What a waste: a global review of solid waste management (Vol. 15, p. 116). World Bank, Washington, DC.

Mohee, R. and Simelane, T. eds., 2015. Future directions of municipal solid waste management in Africa. Africa Institute of South Africa.

Momoh, J.J. and Oladebeye, D.H. (2010). Assessment of Awareness, Attitude and Willingness of people to participate in household solid waste recycling program in Ado-Ekiti, Nigeria. Journal of Applied Sciences in Environmental Sanitation, 5(1).

Mwanza, B. and Mbohwa, C. (2017). Drivers to Sustainable Plastic Solid Waste Recycling: A Review. Procedia Manufacturing, 8, pp.649-656.

Nunnally, J. C., \& Bernstein, I. H. (1994). The assessment of reliability. Psychometric theory, 3(1), 248-292.

Saunders, M. and Thornhill, A., 2004. Trust and mistrust in organizations: An exploration using an organizational justice framework. European Journal of Work and Organizational Psychology, 13(4), pp.493515.

Sidique, S.F., Joshi, S.V. and Lupi, F., 2010. Factors influencing the rate of recycling: An analysis of Minnesota counties. Resources, Conservation and Recycling, 54(4), pp.242-249.

Tomari, R., Kadir, A.A., Zakaria, W.N.W., Zakaria, M.F., Wahab, M.H.A. and Jabbar, M.H., 2017. Development of reverse vending machine (RVM) framework for implementation to a standard recycle bin. Procedia Computer Science, 105, pp.75-80.

Valle, P.O.D., Rebelo, E., Reis, E. and Menezes, J., 2005. Combining behavioral theories to predict recycling involvement. Environment and behavior, 37(3), pp.364-396. 


\section{Appendix}

Table 6: Questionnaire for Citizens

\begin{tabular}{|c|c|}
\hline Items & Questions \\
\hline \multicolumn{2}{|c|}{ Awareness } \\
\hline AW02 & $\begin{array}{l}\text { How aware are you of what a Reverse Vending Machine/Smart bin/Plastic Disposal Machine } \\
\text { does? }\end{array}$ \\
\hline AW03 & $\begin{array}{l}\text { How aware are you of advertisements on hoardings, television or newspaper on Reverse } \\
\text { Vending Machines? }\end{array}$ \\
\hline \multicolumn{2}{|c|}{ Willingness } \\
\hline WI01 & I will always dispose plastic bottles in the Reverse Vending Machine. \\
\hline WI02 & I would dispose plastic bottles in the Reverse Vending Machine even if it is located far away. \\
\hline WI03 & $\begin{array}{l}\text { I will contribute towards the installation of the Reverse Vending Machine in my } \\
\text { locality/organization. }\end{array}$ \\
\hline WI04 & $\begin{array}{l}\text { I will ensure that plastic waste generated by my family is disposed through Reverse Vending } \\
\text { Machines. }\end{array}$ \\
\hline WI05 & I will learn/help others learn to use the Reverse Vending Machine. \\
\hline \multicolumn{2}{|c|}{ Incentives } \\
\hline IN01 & I don't need rewards to keep my surroundings clean \\
\hline IN04 & I feel that rewards like eatables will attract citizens to use Reverse Vending Machines. \\
\hline IN05 & The rewards should be based on where the machine is located. \\
\hline \multicolumn{2}{|c|}{ Convenience } \\
\hline CN01 & People without phones should also be able to use Reverse Vending Machines. \\
\hline $\mathrm{CNO} 2$ & Reverse Vending Machine in my organization is a convenient place for plastic disposal. \\
\hline CN03 & $\begin{array}{l}\text { Children and senior citizens should be able to use the Reverse Vending Machines without } \\
\text { help. }\end{array}$ \\
\hline
\end{tabular}


Proceedings of the World Conference on Waste Management, Vol. 1, Issue 2, 2019, pp. 15-29

\begin{tabular}{|c|c|}
\hline CN04 & $\begin{array}{l}\text { There should be a tutorial video/instruction to guide citizens on how to use Reverse Vending } \\
\text { Machines. }\end{array}$ \\
\hline CN05 & There should be an online feedback form in case of inconveniences. \\
\hline \multicolumn{2}{|c|}{ Involvement } \\
\hline IV01 & I help in disposing waste, even if it is not generated by me. \\
\hline IV02 & I educate my family/friends/colleagues about recycling waste. \\
\hline IV04 & I have contributed to campaigns that promote cleanliness. \\
\hline IV05 & I would promote Reverse Vending Machines through friends/welfare associations/community. \\
\hline IV06 & $\begin{array}{l}\text { I want retailers in my area to adopt Reverse Vending Machines/Smart bins/Waste Disposal } \\
\text { Machines. }\end{array}$ \\
\hline
\end{tabular}

